Cite as: Grohmann, Smith, M.J., C.H., Riccomini, C., 2011. Multi-scale Analysis of Topographic Surface Roughness in the Midland Valley, Scotland. IEEE Transactions on Geoscience and Remote Sensing. 49:1200-1213. DOI:10.1109/TGRS.2010.2053546

(C)2011 IEEE. Personal use of this material is permitted. Permission from IEEE must be obtained for all other users, including reprinting/ republishing this material for advertising or promotional purposes, creating new collective works for resale or redistribution to servers or lists, or reuse of any copyrighted components of this work in other works.

\title{
Multi-scale Analysis of Topographic Surface Roughness in the Midland Valley, Scotland
}

\author{
Carlos H. Grohmann ${ }^{\mathrm{a}}$, Mike J. Smith ${ }^{\mathrm{b}}$, Claudio Riccomini ${ }^{\mathrm{a}}$ \\ ${ }^{a}$ Department of Sedimentary and Environmental Geology, Institute of Geosciences, \\ University of São Paulo, São Paulo, SP, 05508-080, Brazil \\ ${ }^{b}$ School of Geography, Geology and the Environment, Kingston University, \\ Kingston-upon-Thames, Surrey, KT1 2EE, UK
}

\begin{abstract}
Surface roughness is an important geomorphological variable which has been used in the earth and planetary sciences to infer material properties, current/past processes and the time elapsed since formation. No single definition exists, however within the context of geomorphometry we use surface roughness as a expression of the variability of a topographic surface at a given scale, where the scale of analysis is determined by the size of the landforms or geomorphic features of interest. Six techniques for the calculation of surface roughness were selected for an assessment of the parameter's behaviour at different spatial scales and dataset resolutions. Area ratio operated independently of scale, providing consistent results across spatial resolutions. Vector dispersion produced results with increasing roughness and homogenisation of terrain at coarser resolutions and larger window sizes. Standard deviation of residual topography tends to highlight local features and doesn't detect regional relief. Standard deviation of elevation correctly identified breaks-of-slope and was good at detecting regional relief. Standard deviation of slope (SDslope) also correctly identified smooth sloping areas and breaks-of-slope, providing the best results for geomorphological analysis. Standard deviation of profile curvature identified the breaks-of-slope, although not as strongly as SDslope and it is very sensitive to noise and spurious data. In general, SDslope offered good performance at a variety of scales, whilst the simplicity of calculation is perhaps its single greatest benefit.
\end{abstract}

Keywords: Surface roughness, Geomorphometry, Geomorphology, Digital Elevation Model, Digital Terrain Analysis.

Email addresses: guano@usp.br (Carlos H. Grohmann), michael.smith@kingston.ac.uk (Mike J. Smith), riccomin@usp.br (Claudio Riccomini) 


\section{Introduction}

Surface roughness is a key land-surface parameter Olaya (2009) used across the earth and planetary sciences Hobson (1972) to both identify individual landforms and determine the processes acting upon them. For example, roughness-age relationships have been used to delimit landslides of different epochs Mckean and Roering (2004), as well as parameterize hydrological models for channel flow Mason et al. (2003). The surface roughness of a landform is therefore dependent upon the material properties, processes acting upon it and the time elapsed since formation.

A range of methods have been developed for the definition, calculation and application of surface roughness. A single definition of surface roughness may not be possible Hobson (1967), since different types of analysis require different sets of parameters. For example, in remote sensing roughness can be quantified using the reflection of electromagnetic radiation from a surface, ranging from specular to diffuse Lillesand et al. (2004). In geomorphometry Olaya (2009); Pike et al. (2009) roughness is described using surface elevation values and can be used to characterise landforms over a variety of different scales.

Whilst surface roughness remains the most common generic term, a variety of terminology have been applied to its study, including ruggedness Beasom et al. (1983); Washtell et al. (2009), rugosity Jenness (2004); Wilson et al. (2007), microrelief Stone and Dugundji (1965) or microtopography Herzfeld et al. (2000). Throughout this article, we use the term surface roughness as an expression of the variability of a topographic surface at a given scale, where the scale of analysis is determined by the size of the landforms or geomorphic features of interest, either local or regional. This means that if one wishes to study glacial geomorphology, for instance, a surface roughness map highlighting drumlins and eskers is not likely to highlight cirques or U-shaped valleys, and viceversa.

This work specifically focuses upon the broad area of general geomorphology Evans (1972); MacMillan and Shary (2009) and, more explicitly, on a quantification of surface roughness variability using digital elevation models (DEMs). DEMs provide an objective measure of surface elevation (or relief) and are therefore ideally suited to the parameterization of surface features Evans (1980). The wide availability of both high resolution national datasets (e.g. NextMap Britain) and medium resolution global datasets such as SRTM Rabus et al. (2003) or ASTER GDEM Reuter et al. (2009) makes them ideally suited to this type of analysis, although care should be exercised over the suitability of source data Wise (2007). Surface roughness is treated here as a geomorphometric variable, not as a parameter, although the latter has been used frequently in the literature Evans (1972); Minár and Evans (2008); Olaya (2009). A variable is a measurable property of a phenomenon (e.g. slope angle), whilst a parameter is a summary measurement of the characteristics of a population, such as mean slope angle Silk (1979).

In this work, we present a brief summary of the different approaches developed in the study of surface roughness in the earth and planetary sciences. This is followed by an assessment of six selected methods - area ratio, vector dispersion, standard deviation of residual topography $\left(\mathrm{SD}_{\text {restopo }}\right)$, standard deviation of elevation $\left(\mathrm{SD}_{\text {elev }}\right)$, standard deviation of slope $\left(\mathrm{SD}_{\text {slope }}\right)$ and standard deviation of profile curvature $\left(\mathrm{SD}_{\text {profc }}\right)$ - at different scales and spatial resolutions. These assessments are designed to test the application of the above six methods at quantifying roughness at different scales within the landscape, using datasets of differing spatial resolutions. This allows us to make recommendations for their use in geomorphometric studies, with emphasis on the scalability of these methods and suitability of input DEM data. Examples are presented for a study area in the Midland Valley, Scotland.

\subsection{Study Area}

The study area is located in the Midland Valley of Scotland, north of Glasgow (Fig. 1). Elevation ranges from sea level to $\sim 700 \mathrm{~m}$ in the northwest sector, near Loch Lomond. The region was last glaciated during the Last Glacial Maximum $(\sim 20 \mathrm{ka} B P)$ and, in the area around Loch Lomond, during the Younger Dryas glaciation ( 12 ka BP). The study area is primarily covered by till, excluding the summits of the Kilpatrick Hills and Campsie Fells. The river valleys are covered with glaciofluvial and glaciolacustrine deposits Rose (2008). Glacier bedforms, primarily 
formed in areas of till, cover large areas of the region. The mix of small scale (drumlins) and large scale (scarps) relief makes this an ideal region to study the effects of spatial resolution and the scale of analysis on roughness calculations.

A sub-area (inset in Fig. 1B) was selected to calculate descriptive statistics and is enlarged in Fig. 1C, 3A-D, 4 and 5. In this sub-area, the main topographic features are the Campsie Fells, in the northeast sector and the Kilpatrick Hills, in the southwest. Small urban areas are found across the valley between the hills, in addition to an extensive patchwork of forests. This adds "surface clutter" to the DEM and is designed to test the sensitivity of roughness measures to these types of features.
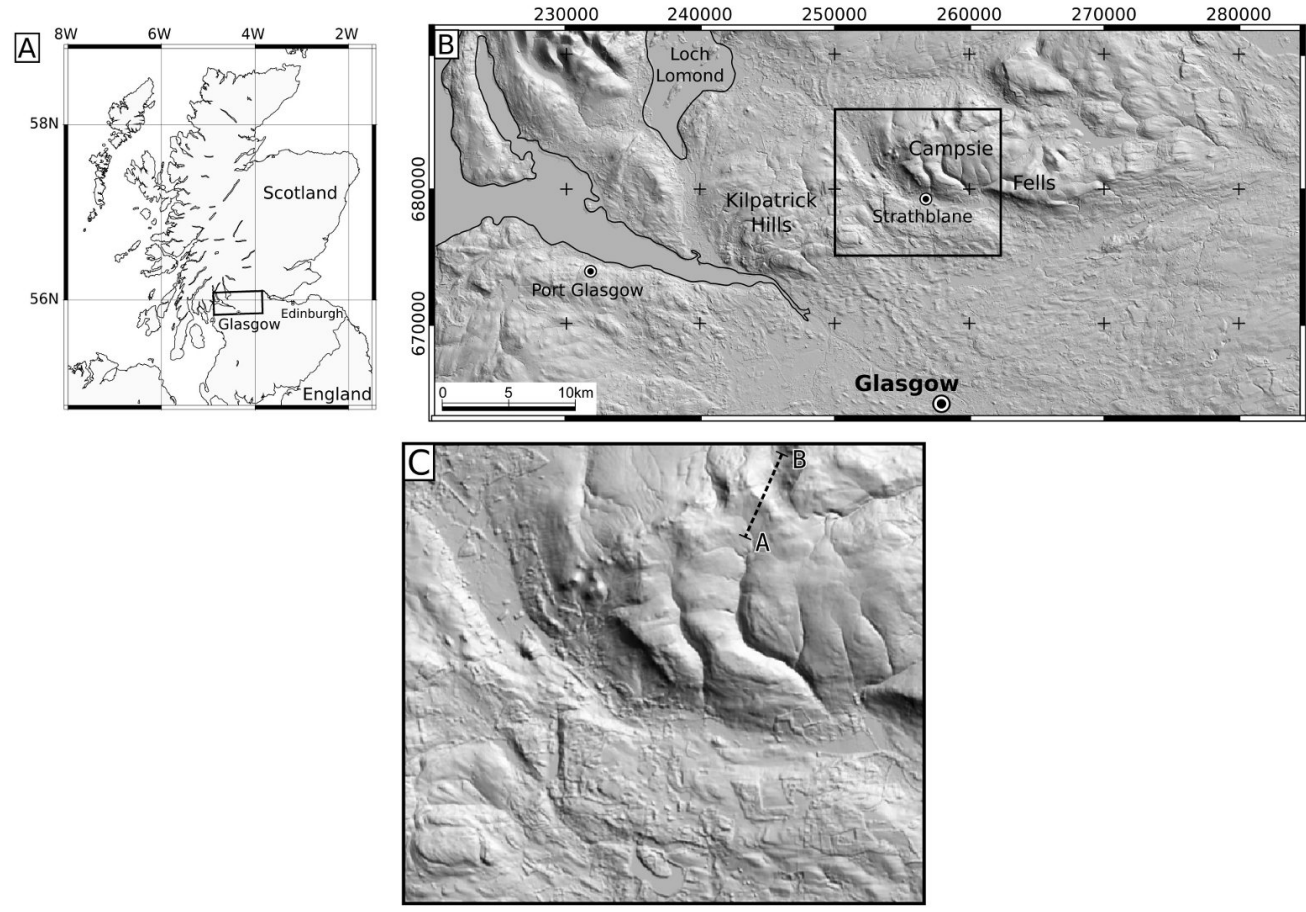

Figure 1. Shaded relief image depicting the location of the study area (illumination $045^{\circ}$, elevation $30^{\circ}$, no vertical exaggeration). A-B line in C marks the profile of figure 9.

\subsection{Measures of Surface Roughness}

In this section, we provide a synopsis of the different definitions, methods and applications of surface roughness. This is intended to familiarize the reader with common methods found in the literature, not to provide an extensive review of the subject.

The area ratio evaluates the similarities between the surface (real) area and flat (plan) area of square cells or triangles defined by input points, by calculating the ratio of these values. Flat surfaces would present values close to one, whilst with irregular surfaces the ratio shows a curvilinear relationship which asymptotically approaches infinity as the real area increases Hobson (1967).

Different measurements of vector dispersion (or orientation) are used as a proxy for surface roughness Hobson (1967, 1972); Day (1979); Philip and Watson (1986); Guth (2003); Mckean and Roering (2004). An array of regularly spaced elevation values can be divided into planar triangular surfaces (defined by three adjacent non-collinear points) and normals to these planes represented by unit vectors. Values of vector mean, strength $(R)$ and dispersion $(k)$ can be calculated for each square cell. In smooth areas, with similar elevations, vector strength is expected to be high and vector dispersion to be low, since the vectors will become parallel, as $R$ approaches $N$ (number of vectors). In rough areas, the non-systematic variation in elevation readings will result in low 
vector strength and high vector dispersion. To Mark (1975), planar areas should have a roughness value of zero, so the inverse of $k$ would be a better representation of roughness measure.

Several authors define surface roughness in terms of the variability of elevation values, generally expressed as the absolute standard deviation of all values within a window, or as the deviation from a best-fit plane. It has been applied to data such as raw elevation points Hobson (1972), DEMs Evans (1984); Haneberg et al. (2005); Glenn et al. (2006); Frankel and Dolan (2007); Arrell and Carver (2009), satellite imagery Beyer et al. (2003); Cord et al. (2007), bathymetric data Dartnell and Gardner (2004); Valentine et al. (2004); Lundblad et al. (2006); Wilson et al. (2007) or elevation profiles Van Der Veen et al. (1998); Kreslavsky and Head (2000); Shepard et al. (2001). Standard deviation of residual topography was used as a measure of roughness by Haneberg et al. (2005); Haneberg (2007); Cavalli et al. (2008), where the residual topography is the difference between the original and a smoothed DEM (an approach similar to the deviation of values from a best-fit plane).

Curvature is the second derivative of the altitude or elevation surface and is comprised of three elements: profile, planform and tangential curvature Schmidt et al. (2003). Of particular interest is profile curvature as this measures downslope curvature and helps identify breaks-of-slope and therefore potentially roughness. The standard deviation of both planform and profile curvatures were used as part of a study on multi-dimensional terrain characterization, were profile curvature (the rate of change of slope) was related to roughness and planform curvature (the rate of change of aspect), to drainage density Evans (1984, 1998).

Other methods employed to determine surface roughness include fourier analysis Stone and Dugundji (1965); Fox and Hayes (1984); Hubbard et al. (2000); Siegert et al. (2004); Taylor et al. (2004); Bingham and Siegert (2009), geostatistics Philip and Watson (1986); Herzfeld et al. (2000); Siska et al. (2005) the fractal dimension of a surface Elliot (1989); Taud and Parrot (2005) and entropy Gorini (2009); Papasaika and Baltsavias (2009).

The above approaches can be broadly classified as array or profile based. Array based techniques are applied regionally to 2-dimensional input data. Profile based techniques are based up on a single set of values, usually field-surveyed profiles, and are 1-dimensional. The resultant output can be presented as either a grid, where the results show the variation of values in space, or as summary statistics, either calculated from all points in the area or from local profiles.

The methods outlined above were reviewed in order to discard those that were not appropriate for geomorphometric analysis. Procedures based upon profile data (e.g. fourier analysis) were rejected as they provide limited, 1-dimensional, information. Additionally the variability of landform orientation may lead to overestimation of wavelength when linear features are sampled at any angle other than perpendicular to strike. This may not be a problem in small, field-surveyed profiles, but certainly applies to remotely sensed data, such as echo-sounding bathymetry.

The spatial variability of geomorphometric variables is important - it is not enough to know that a given area is "rougher" or "smoother" than another, but rather how much and where this difference happens, since it may be related to geological features such as lithological boundaries and [neo]tectonic structures, which could be masked in a hypsometric map, as a consequence of altimetric variations and of the altitude intervals chosen to generate the map Grohmann (2004). Therefore, only array-based methods were considered in our analysis.

The area ratio, vector dispersion, standard deviation of elevation, standard deviation of residual topography, standard deviation of slope and standard deviation of profile curvature methods were selected for our analysis. These methods are suited to array-based calculations using DEMs as primary input data and were implemented as sequences of neighbourhood (i.e. moving-window) and raster map algebra analysis steps. Moving-window operators were adopted because the morphometric variable is calculated for all input cells, so there is no risk of "missing" any terrain feature Grohmann and Riccomini (2009). The flexibility of array-based calculations also means that a multi-scale study can be performed by changing the neighbourhood size or by resampling the original data.

The expected relationship between DEM spatial resolution and moving-window size for surface roughness measurements is schematically presented in Fig. 2. For a hypothetical topographic profile, DEM resolution is represented by straight line segments, and decreased two-fold each 
time, from top to bottom. Vectors normal to surface "cells" are shown as arrows. Movingwindows are illustrated by rectangles and their size is related with the topmost "DEM" (1x). Roughness is given as shades of grey, where light tones represent smooth surfaces and dark tones, rough areas. With small windows, only the breaks-of-slope (local relief) are marked with high roughness values. As the window size increases, larger relief features (such as scarps) tend to be included in the high value areas, although there is a point where the window size becomes bigger than the landforms of interest in the area, in which case it will not be possible to discriminate the response of these features. Additionally, depending upon the characteristics of the area (e.g. large plains or structural surfaces) the altimetric variation of different geomorphic domains may be so small that other parameters would be necessary in order to identify them.

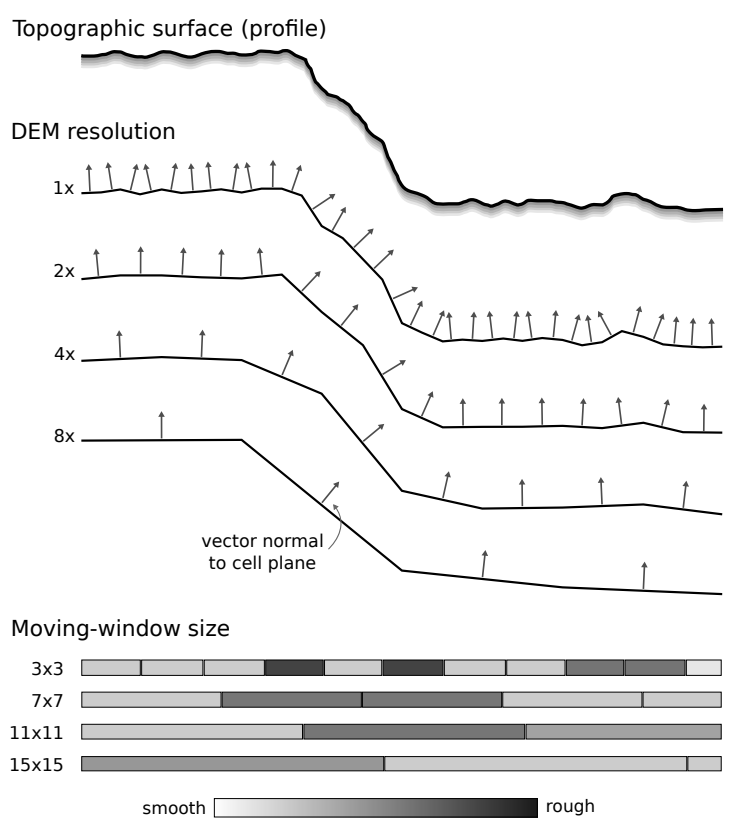

Figure 2. Schematic representation of surface roughness measures variation according to spatial resolution of DEM and moving-window size.

Given the variety of approaches for calculating surface roughness, in this section we have selected six primary methods for a comparative assessment. These are subsequently evaluated at different scales and across spatial resolutions, with qualitative and quantitative results presented.

\section{Methodology}

As this study is restricted to evaluating array-based geomorphometric methods for calculating surface roughness, an input DEM is required for further analysis. DEM selection criteria were based around spatial resolution and geographic location, with a high spatial resolution DEM required in order to test the above algorithms across a range of resolutions and within a study area presenting multi-scale roughness features. The NEXTMap Britain Smith et al. (2006) DEM was considered suitable as the input dataset. This product was acquired and produced by Intermap Technologies using airborne interferometric synthetic aperture radar (InSAR), at a spatial resolution of $5 \mathrm{~m}$, with a vertical accuracy of $0.5-1 \mathrm{~m}$ and horizontal accuracy of $2 \mathrm{~m}$. It is therefore at a sufficient spatial resolution for multi-scale evaluation and, as a product with extensive coverage, is available for any part of the Western Europe.

To evaluate the effects of spatial resolution, the original DEM was resampled by calculating the mean elevation value at resolutions of 10, 25, 50 and $100 \mathrm{~m}$. This is intended to simulate data acquired by sensors with different spatial resolutions; as such, it is appropriate that the elevation 
value is the average of the actual elevations within the cell. To evaluate scale effects of roughness, the selected methods were applied to all DEMs using moving-windows of $3 \times 3,5 \times 5,7 \times 7,9 \times 9$, 11x11, 13x13, 15x15, 17x17, 19x19, 21x21, 31x31 and 51x51 cells. Roughness was calculated for the 5 resolutions and 12 window sizes, using the 6 methods outlined above, giving a total of 360 individual model runs.

To calculate area ratio, the surface area of individual cells was calculated according to Grohmann (2004), from the trigonometric relationships between the square (horizontal) pixel and its inclined projection, given by slope. Temporary layers with the sum of values within a neighbourhood for plan and real area were used to calculate the final ratio.

To calculate vector strength $(R)$ and dispersion $(1 / k)$, compass-oriented aspect (the default in GRASS is cartesian-oriented, with $0^{\circ}$ at East and increasing counter-clockwise), colatitude $\left(90^{\circ}\right.$ - slope), direction cosines (Eq. 1) and sum of direction cosines in a neighbourhood (Eq. 2) were calculated. Vector strength was derived according to 3 and vector dispersion as the inverse of 4 Mark (1975).

$$
\begin{gathered}
x_{i}=\sin \theta_{i} \cos \phi_{i} \quad y_{i}=\sin \theta_{i} \sin \phi_{i} \quad z_{i}=\cos \theta_{i} \\
\bar{x}=\sum_{i=1}^{N} x_{i} \quad \bar{y}=\sum_{i=1}^{N} y_{i} \quad \bar{z}=\sum_{i=1}^{N} z_{i} \\
R=\sqrt{\bar{x}^{2}+\bar{y}^{2}+\bar{z}^{2}} \\
k=(N-1) /(N-R)
\end{gathered}
$$

Residual topography was obtained by subtracting the DEM for each spatial resolution from an averaged version, calculated at each moving-window size.

Slope, aspect and profile curvature were calculated in GRASS using formulas by Horn (1981). To avoid potencial bias of aspect in 0, 45, 90,.., 360 directions Neteler and Mitasova (2008); Hofierka et al. (2009), all DEMs were set to have floating-point precision.

Standard deviation outputs were calculated using common moving-window tools. These methods were implemented as shell scripts in GRASS-GIS Neteler and Mitasova (2008); GRASS Development Team (2009), as sequences of neighbourhood (i.e., moving-window) and raster map algebra analysis steps. Shell scripts for area ratio and vector dispersion calculations are available for download at the GRASS Wiki site ${ }^{1}$.

\section{Results}

Initial results are depicted in Fig. 3A-F, where surface roughness, calculated using a $11 \times 11$ moving-window over the DEM with $10 \mathrm{~m}$ spatial resolution, are presented for the selected methods sorted according to those based directly on elevation values (area ratio, vector dispersion, $\mathrm{SD}_{\text {restopo }}$, $\left.\mathrm{SD}_{\text {elev }}\right)$ and those based on derivatives of the elevation $\left(\mathrm{SD}_{\text {slope }}, \mathrm{SD}_{\text {profc }}\right)$. Shades of yellow correspond to smoother areas, green-blue tones to intermediate values and purple-red to rough areas. It should be noted that the original roughness values were normalized, in order to provide a direct comparison between the maps.

For the area ratio output (Fig. 3A), the predominance of cyan tones in an area of low relief indicates that this method fails to distinguish features with similar elevation. The scarps of Campsie Fells are marked with high roughness values, since they have steep slope angles, even though they may be considered as smooth [inclined] surfaces.

In the vector dispersion output (Fig. 3B), the predominance of blue-purple tones indicates the sensitivity of this method to small-scale (i.e. local) variations in elevation, which are common in

\footnotetext{
${ }^{1}$ http://grass.osgeo.org/wiki/GRASS_AddOns
} 

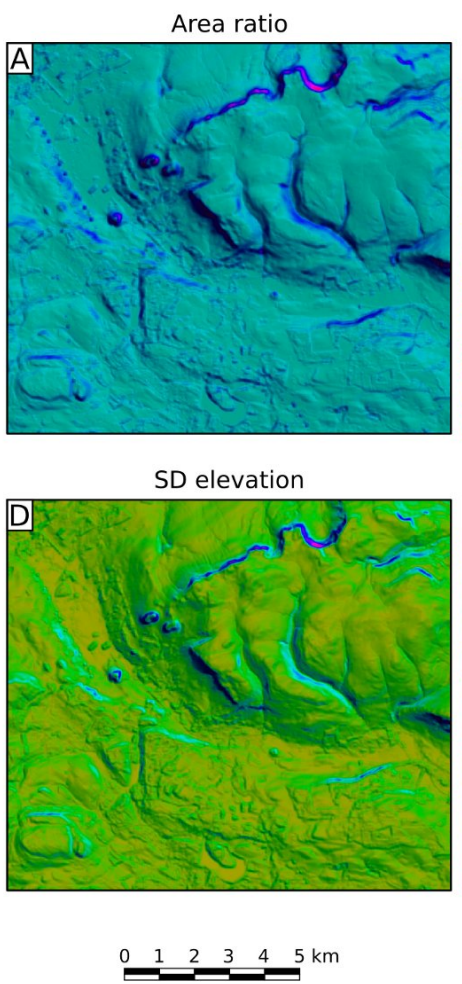

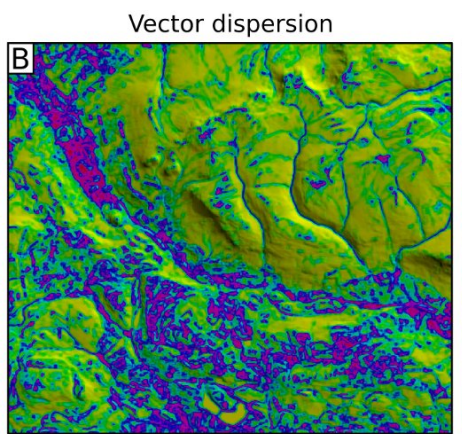

SD slope
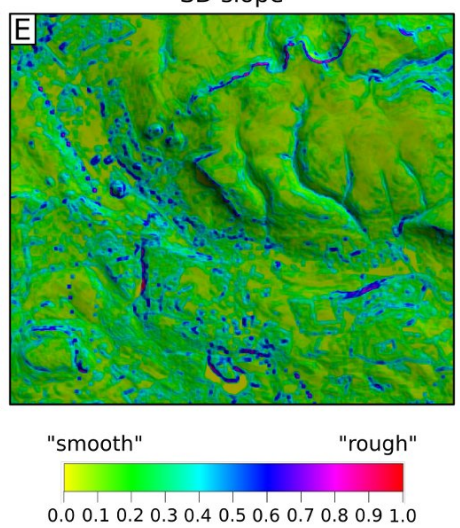

SD residual topography

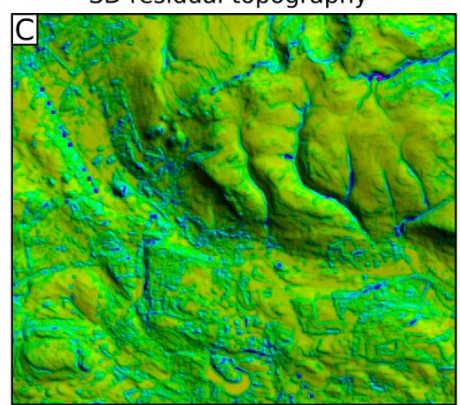

SD profile curvature

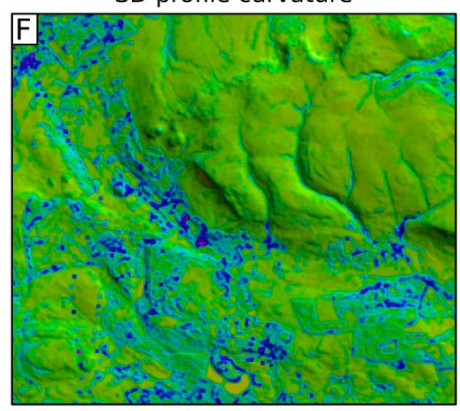

Normalized_values $=\frac{(\text { map_value }- \text { map_min })}{(\text { map_max }- \text { map_min })}$

Figure 3. Sample output for surface roughness calculations. A) area ratio; B) vector dispersion (1/k); C) standard deviation of elevation $\left.\left(\mathrm{SD}_{\text {elev }}\right) ; \mathrm{D}\right)$ standard deviation of slope $\left(\mathrm{SD}_{\text {slope }}\right)$; $\left.\mathrm{E}\right)$ standard deviation of profile curvature $\left.\left(\mathrm{SD}_{\text {profc }}\right) ; \mathrm{F}\right)$ standard deviation of residual topography $\left(\mathrm{SD}_{\text {restopo }}\right)$. All outputs were calculated using a $11 \times 11$ neighbourhood for the $10 \mathrm{~m}$ DEM.

InSAR datasets over vegetated and urban areas. In this image the scarps of the Campsie Fells are depicted as smooth areas, with low vector dispersion.

$\mathrm{SD}_{\text {restopo }}$ (Fig. 3C) identifies the break-of-slope of Campsie Fells scarps, although not as well as $\mathrm{SD}_{\text {slope }}$. Urban and vegetated areas show intermediate to low values (green-cyan tones).

The output for $\mathrm{SD}_{\text {elev }}$ (Fig. 3D) show a predominance of low values (yellow-green tones), with the scarps of the Campsie Fells marked with high values due to the steep slopes. This method is also sensitive to local strong variations in elevation, which can be caused by spurious data. It is worth noting that area ratio and $\mathrm{SD}_{\text {elev }}$ delimit forest stands. Both these methods would benefit from simple contrast stretches to better visualise the data.

$\mathrm{SD}_{\text {slope }}$ (Fig. $3 \mathrm{E}$ ) is sensitive to sudden changes in the original slope values, and highlights the boundaries of urban and forest areas. The scarps of the Campsie Fells are correctly identified as smooth areas, with high values located over the slope break, indicating that this method is suitable for terrain analysis.

$\mathrm{SD}_{\text {profc }}$ (Fig. 3F) does not identifies the slope break of the Campsie Fells scarps. The higher values are found in urban and vegetated areas, indicating a sensitivity to strong variations in slope.

The effect of changing the spatial resolution of the DEM and moving window size is illustrated for vector dispersion, $\mathrm{SD}_{\text {slope }}$ and $\mathrm{SD}_{\text {restopo }}$ in Figs. 4 and 5. Figs. 6 and 7 also presents summary statistics for all model runs; median values are used in the plots, since all outputs present an asymmetric distribution. Fig. $6 \mathrm{ABC}$ and Fig. $7 \mathrm{ABC}$ shows median roughness curves for window size, across all DEM resolutions. Fig. 6DEF and Fig. 7DEF provides the same summary for standard deviation. Fig. 8 depicts density plots Cox (2007) of roughness values for four DEM resolutions $(10,25,50$ and $100 \mathrm{~m})$ at all window sizes.

Our tests demonstrate that for area ratio the broad pattern of roughness does not change 

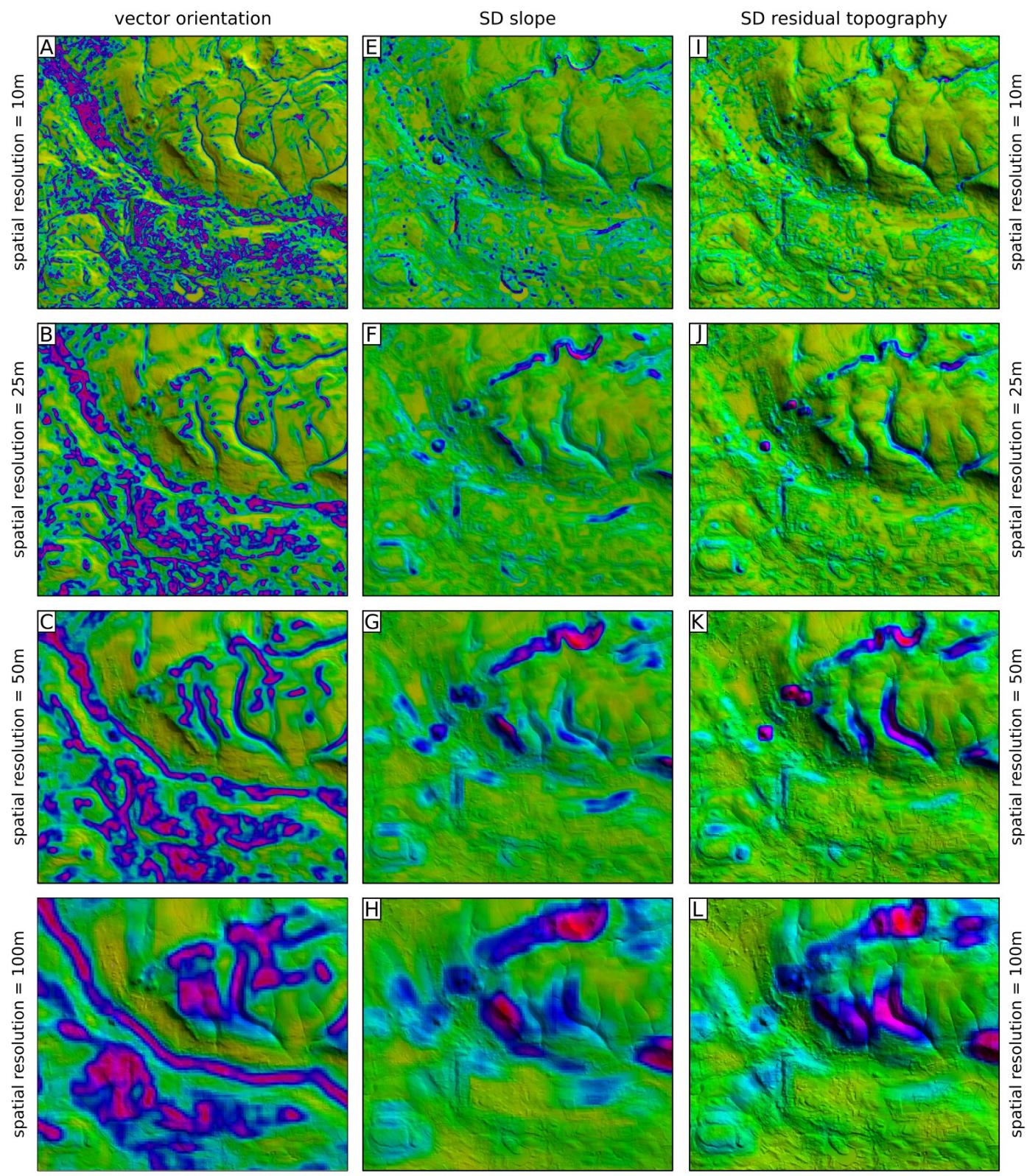

moving-window size $=11 \times 11$

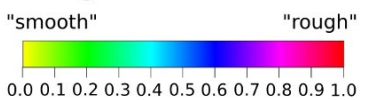

Normalized_values $=\frac{(\text { map_value }- \text { map_min })}{(\text { map_max }- \text { map_min })}$

0.00 .10 .20 .30 .40 .50 .60 .70 .80 .91 .0

Figure 4. Effect of changing spatial resolution of the input DEM. Output calculated using a 11x11 moving window.

across scales or window sizes. Median values remain approximate constant across window sizes (Fig. 6A) as well as the peaks of density curves (Figs. 8A-D), although the mean roughness value increase with decreasing spatial resolutions. The standard deviation shows a tendency to increase with window size. Whilst smoothing does occur at coarser resolutions and larger window sizes, area ratio is generally scale independent.

The results for vector dispersion show a more complex relationship with resolution and window size. As resolution decreases and window size increases, roughness increases (Fig. 6C). Roughness 
values for a 3x3 window are similar in all resolutions, and grow fast, as if following a power-law. Standard deviation values (Fig. 6D) increase rapidly for small windows and tent to decrease for windows larger than $11 \times 11$. Density plots (Fig. 8E-H) show a transition from positive skewed, unimodal distributions for small windows to more symetrical distributions for large windows. As the spatial resolution decreases, density curves for large windows tend to present more than one peak. The north scarps of the Campsie Fells continue to present low roughness values as resolution decreases and the areas of intermediate to high values in the south scarp tend to be eliminated as landforms become generalised. In the south area, the presence of smooth (open fields) and rough (urban/vegetated) features produces mixed results as the resolution is reduced. Whilst vector dispersion is less sensitive to outliers, it only depicts roughness at certain scales and doesn't identify regional roughness features (i.e. mountain blocks). Unlike area ratio, it does (correctly) depict uniform slopes as smooth.

$\mathrm{SD}_{\text {restopo }}$ show an increase in median values with increasing window sizes. For windows from $13 \times 13$ to $21 \times 21$, an inversion in the general behaviour of roughness values for resolutions of 10 $\mathrm{m}$ and $25 \mathrm{~m}$ is observed, where the values for the $25 \mathrm{~m}$ DEM are lower than the values for the $10 \mathrm{~m}$ DEM. With smaller $(3 \times 3$ to $11 \times 11)$ and larger $(31 \times 31$ and $51 \times 51)$ windows, values for the $25 \mathrm{~m}$ DEM are higher than those for the $10 \mathrm{~m}$ DEM (Fig. 6E). Standard deviation shows a tendency to increase with window size up to $21 \times 21$, where it stabilizes. The stacking pattern of the curves is better defined than for $\mathrm{SD}_{\text {profc }}$ (Fig. 6F). Density plots (Fig. 8I-L) show positive skewed distributions with a peak at about the same value (0.1) for all resolutions and window sizes, except for large windows $(31 \times 31,51 \times 51)$ at low resolutions $(50 \mathrm{~m}, 100 \mathrm{~m})$.

$\mathrm{SD}_{\text {elev }}$ shows an increase in roughness (and standard deviation) as resolution decreases and window size increases, with the effect greater at coarser resolutions (Figs. 7A and B). In particular, breaks-of-slope are identified so that at coarser resolutions and larger window sizes, regional relief is identified. Density plots (Fig. 8M-P) show positive skewed distributions through all resolutions and window sizes, except for larger windows $(31 \times 31,51 \times 51)$ at low resolutions $(50 \mathrm{~m}, 100 \mathrm{~m})$, where the distribution becomes less skewed and essentially bimodal, with distinct peaks for low and high roughness values.

$\mathrm{SD}_{\text {slope }}$ shows an increase in roughness as window size increases, although the spatial resolution of the dataset does not appear to influence the output (Fig. 7C). Standard deviation of $\mathrm{SD}_{\text {slope }}$ shows a tendency to increase with a decrease in resolution and increase in window size (Fig. 7D). Density plots (Fig. 8Q-T) exhibit a transition from unimodal distributions to bimodal or multimodal distributions with increasing window size, a behaviour enhanced at low spatial resolutions. High values of $\mathrm{SD}_{\text {slope }}$ in output with large window sizes tend to concentrate around areas with high values in output with small window sizes.

$\mathrm{SD}_{\text {profc }}$ yielded mixed results. As median values tend to increase with window size, the spatial resolution does not follow a pattern, with higher values for intermediate resolution (25 m) lower values for high resolutions $(5,10 \mathrm{~m})$ and intermediate values for lower $(50,100 \mathrm{~m})$ resolutions (Fig. 7E). Standard deviation increases with window sizes up to $13 \times 13$ and then tends to stabilize. Again, spatial resolution does not follow a clear pattern, as that observed by the stacking of curves for other methods (Fig. 7F). Density plots (Fig. 8U-X) show positive skewed distributions for small windows and less skewed distributions for large windows. Interestingly, with $50 \mathrm{~m}$ spatial resolution, density curves for windows from $11 \times 11$ to $21 \times 21$ pixels (Fig. 8W) present a peak at about the same value.

\section{Discussion}

The previous section has presented initial results for calculations of roughness at five sample resolutions and twelve window sizes using six primary methods.

Fig. 6A-C-E and Fig. 7A-C-E demonstrates that, in general, all methods, except area ratio, have a tendency for an increasing median with increasing neighbourhood size. $\mathrm{SD}_{\text {elev }}$ and $\mathrm{SD}_{\text {slope }}$ follow a linear trend, whilst vector dispersion, $\mathrm{SD}_{\text {profc }}$ and $\mathrm{SD}_{\text {restopo }}$ appear to follow a power-law.

The vertical stacking of curves in the plots shows the influence of spatial resolution in the calculated values. One exception to this is the $5 \mathrm{~m}$ vector dispersion curve (Fig. $6 \mathrm{C}$ ), where the 

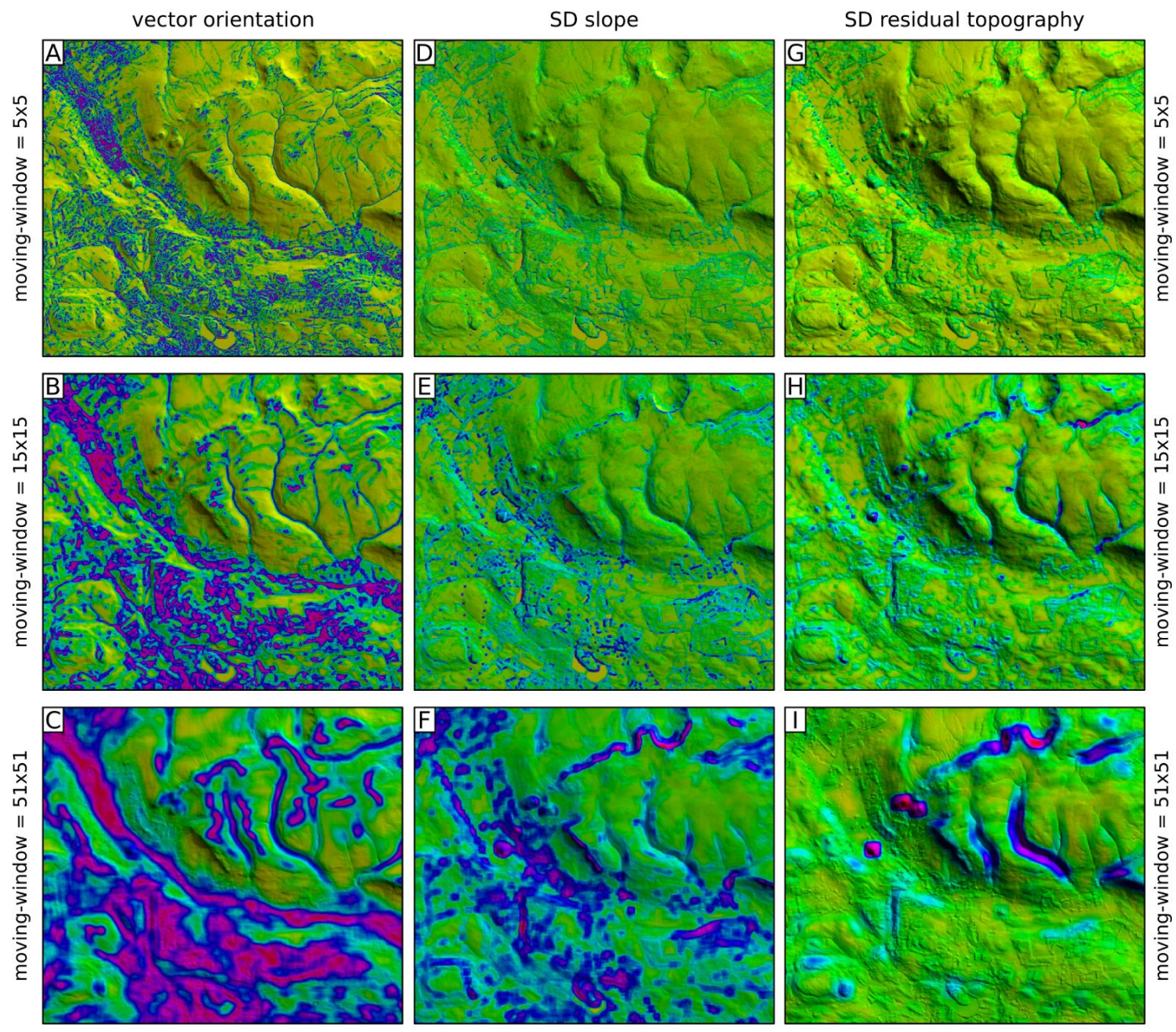

spatial resolution $=10 \mathrm{~m}$
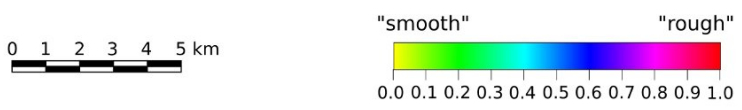

Normalized_values $=\frac{\text { (map_value }- \text { map_min })}{(\text { map_max }- \text { map_min })}$

0.00 .10 .20 .30 .40 .50 .60 .70 .80 .91 .0

Figure 5. Effect of changing moving-window size. Output calculated over the DEM with $10 \mathrm{~m}$ spatial resolution.

values increase faster than those of coarser DEMs, eventually converging to the values of the 10 $\mathrm{m}$ DEM, with a window size of $51 \times 51$ cells. This is interpreted as being related to abrupt changes in elevation (and therefore high vector dispersion) due to "surface clutter" (specifically urban and vegetation features), which are well defined at the original DEM resolution of $5 \mathrm{~m}$. These features are progressively smoothed as the resolution decreases.

Additionally, all vector dispersion curves have similar values for the $3 \times 3$ window. In a $3 \times 3$ neighbourhood, vector dispersion is generally small, regardless of the spatial resolution, except at the edges of features where there are strong variations of slope. This occurs around vegetation and urban areas for the fine resolution DEMs, or around steep scarps for the coarse DEMs. An increase in the moving-window size to $5 \times 5$ or $7 \times 7$ is enough to produce different results across the range of spatial resolutions. Fig. 6D show that the standard deviation of vector dispersion tends to decrease as the neighbourhood size increases, although the values increase slightly prior to decline. This initial growth is explained by the moving-window size (as with the vector dispersion values) where $3 \times 3$ windows are less sensitive to spatial resolution changes.

These result agree with Tobler's First Law of Geography that Tobler (1970), near things are more related than distant things. Therefore elevation values within a small window should be 

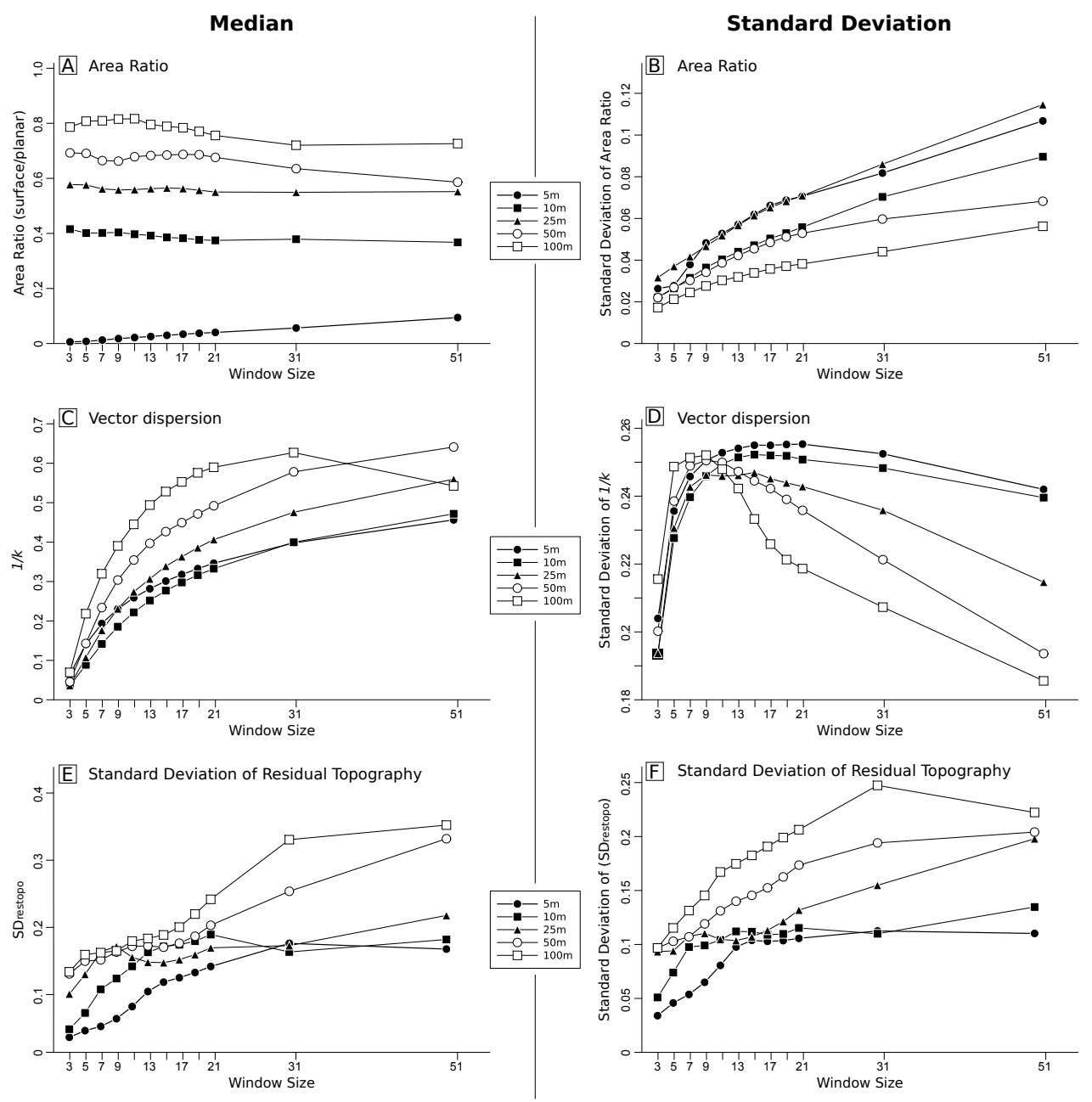

Figure 6. Plots of median and standard deviation values of surface roughness according to DEM spatial resolution and moving-window size.

similar with a correspondingly low standard deviation.

Fig. 9 shows the behaviour of the selected surface roughness methods in a SSW-NNE profile across the north scarps of Campsie Fells (profile location on Fig. 1C). In the top plot, area ratio and $\mathrm{SD}_{\text {elev }}$ show high values at the smooth, steep slope of the scarp. Besides the central peak, area ratio values remain approximate constant, whereas $\mathrm{SD}_{\text {elev }}$ shows more variation. In the central plot, $\mathrm{SD}_{\text {slope }}$ has two distinct peaks corresponding to the breaks-of-slope of the scarp and minor peaks related to smaller terrain features. $\mathrm{SD}_{\text {profc }}$ also show the same peaks, although the roughness values are about half of $\mathrm{SD}_{\text {slope }}$. In the bottom plot, vector orientation has two main peaks, one at the upper break-of-slope of Campsie Fells and one located over a small terrain feature to SSW (left on the plots), which didn't received such high values with the other methods. $\mathrm{SD}_{\text {restopo }}$ marks the upper break-of-slope, although the lower break is not well defined.

In summary, area ratio operates independently of scale, providing a consistent result which means that coarser resolution DEMs should produce similar results to detailed DEMs. This is a significant advantage, although it should be noted that steep, smooth, slopes will appear as rough terrain. Vector dispersion produces a much wider range of results with increasing roughness (and homogenization of terrain) at coarser resolutions and larger window sizes. Whilst steep, smooth, slopes will have low roughness values, breaks-of-slope are not readily delimited and regional relief is more difficult to identify. However vector dispersion is good at identifying fine-scale roughness 

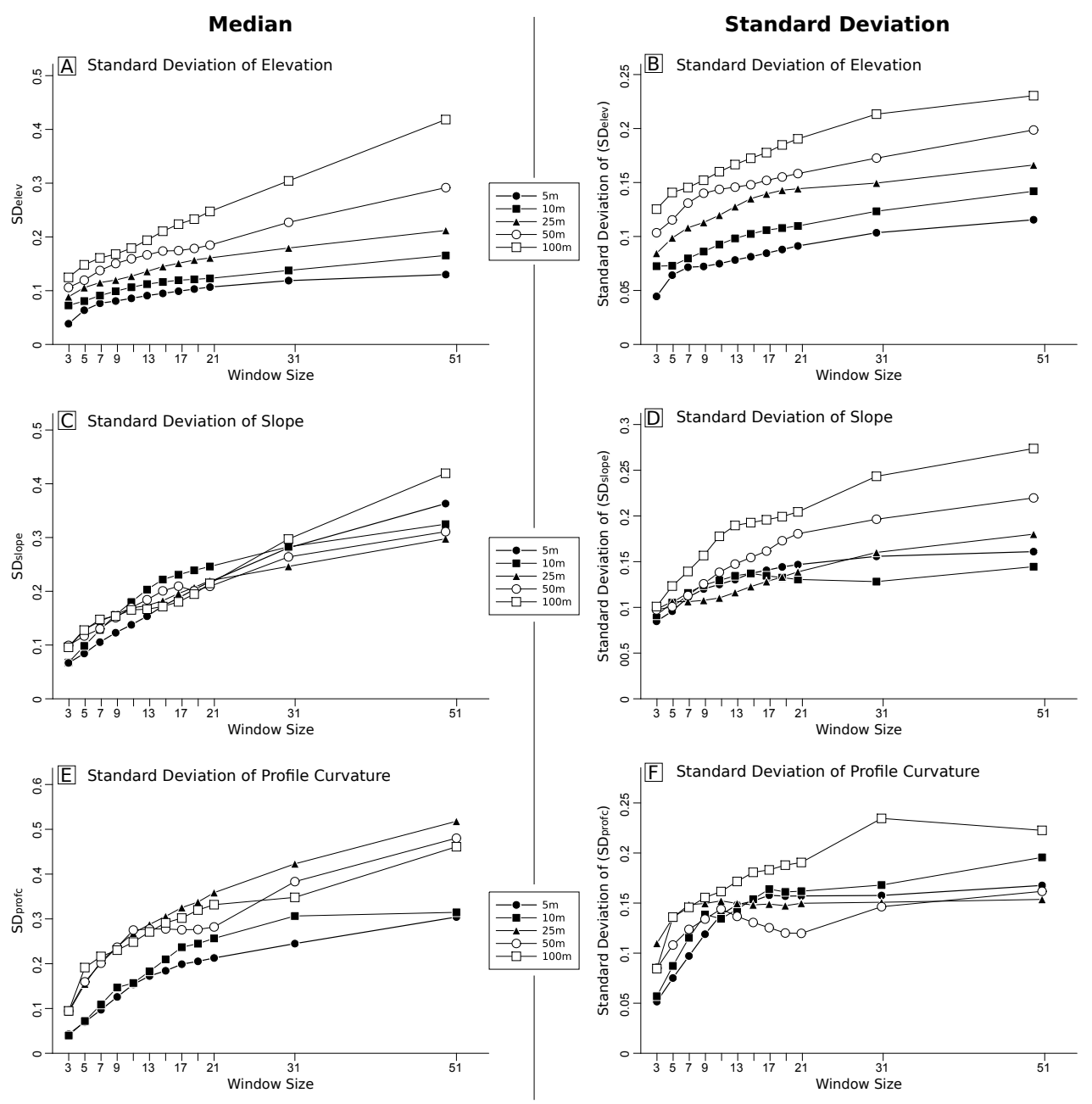

Figure 7. Plots of median and standard deviation values of surface roughness according to DEM spatial resolution and moving-window size.

features and there is the potential for its use in automating the removal of "surface clutter" from DEMs. $\mathrm{SD}_{\text {restopo }}$ tends to highlight local features and doesn't detect regional relief Hiller and Smith (2008).

With large window sizes, $\mathrm{SD}_{\text {elev }}$ identifies breaks-of-slope and could be used to detect regional relief. At fine resolutions and small window sizes it remains good at identifying small features, although standard image processing techniques (such as contrast stretches) may be required to emphasise them. $\mathrm{SD}_{\text {slope }}$ correctly identifies steep smooth slopes and areas of "surface clutter" (e.g. forest stands) whilst also identifying breaks-of-slope across scales. In addition to good performance at a variety of scales, both $\mathrm{SD}_{\text {elev }}$ and $\mathrm{SD}_{\text {slope }}$ benefit from the simplicity of the calculation, although any noise or error in the original elevation data may be enhanced. $\mathrm{SD}_{\text {profc }}$ identified the breaks-of-slope, although not as strongly as $\mathrm{SD}_{\text {slope }}$ and it is very sensitive to noise and spurious data, as small errors in input DEMs can potentially lead to large errors in derivative products (e.g. aspect, slope, curvature) and, indeed, these can be used to assess DEM quality Wise (2000) . 

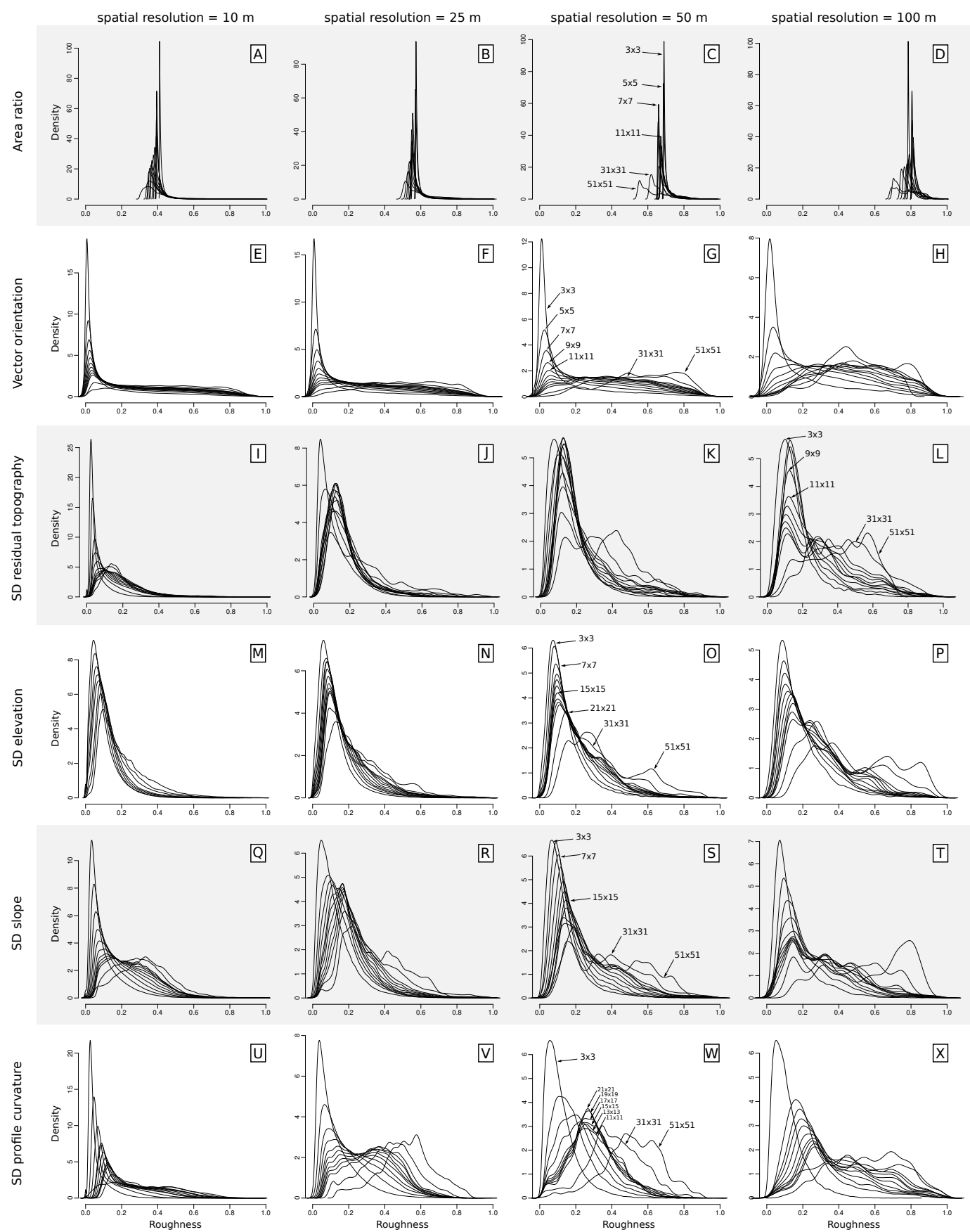

Figure 8. Density curves for the selected roughness methods plotted at four spatial resolutions (10, 25, 50 and $100 \mathrm{~m}$ ) for 12 moving window sizes.

\section{Conclusions}

Surface roughness is commonly used in the earth and planetary sciences as an explanatory variable. It is dependent upon material properties, current and palaeo processes and the time elapsed since formation. Six common measures of surface roughness - area ratio, vector dispersion, standard deviation of residual topography, standard deviation of elevation, standard deviation of slope and standard deviation of profile curvature - have been implemented using common GIS 


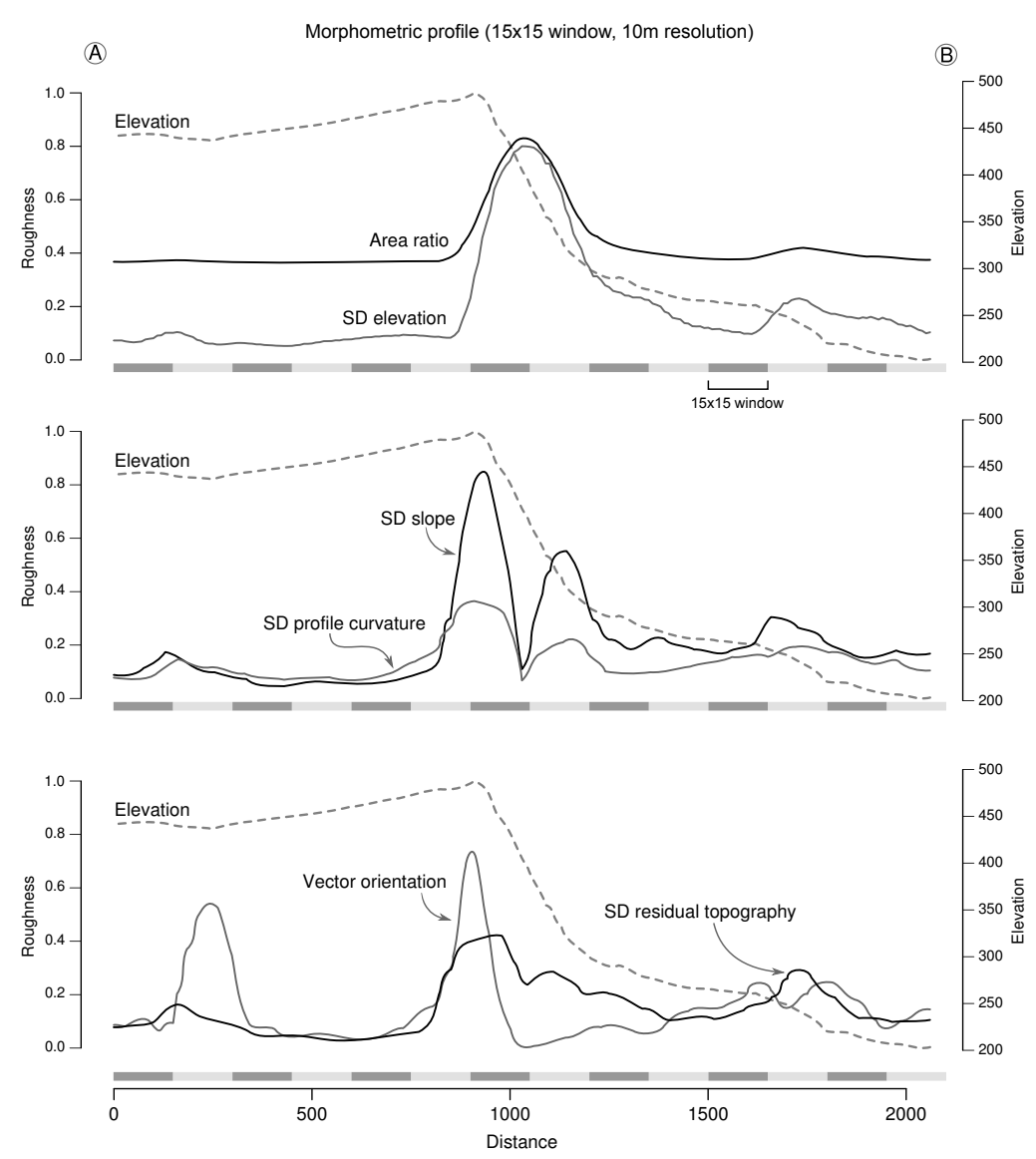

Figure 9. Morphometric profile for the six selected methods of surface roughness across the north scarps of Campsie Fells.

tools. The widespread availability of DEMs allows the fast and inexpensive multi-scale analysis of surface roughness.

Standard deviation of slope, standard deviation of profile curvature and vector dispersion provide good results, depicting most terrain features, standard deviation of elevation and standard deviation of residual topography have an intermediate performance, whilst area ratio fails to distinguish between landforms in areas of low relief. Both area ratio, standard deviation of elevation and standard deviation of profile curvature are sensitive to abrupt strong variations in elevation, which can be caused by spurious data.

Inclined smooth surfaces, such as hillslopes, will have high values for area ratio and standard deviation of elevation calculations, but low values for vector dispersion, standard deviation of slope and standard deviation of profile curvature calculations. Vector dispersion and standard deviation of slope calculated using $3 \times 3$ windows have similar median values, regardless of the spatial resolution, whereas $5 \times 5$ or $7 \times 7$ windows were sufficient to produce different results at different spatial resolutions.

Neighbourhood size plays an important role, along with spatial resolution, in determining which features will be identified, and thus, the scale of analysis. There is little advantage in using a detailed, fine-resolution DEM, as a large neighbourhood will be required and the number of cells within the window grows exponentially, which dramatically increases the computational time involved in roughness calculations.

Standard deviation of slope remains the single most effective measure of surface roughness due to the simplicity of calculation, detection of fine scale/regional relief and performance at a variety of scales. 


\section{Acknowledgment}

This study was supported by Brazil's Ministry of Education Grant CAPES/PDEE-BEX 5176/069 and State of São Paulo Research Foundation Grants FAPESP 04/06260-5 and 09/09881-4 to Grohmann. Riccomini is a Research Fellow of the National Council of Scientific and Technological Development, CNPq Grant 304649/2005-8. This study was presented in earlier versions at the $33^{\text {rd }}$ International Geological Congress, held at Oslo (Norway), and at the Geomorphometry 2009 Conference, held at Zürich University (Zürich, Switzerland). We gratefully acknowledge Intermap Technologies for the supply of NextMap Britain data. Thanks are extended to Ian Evans and Marco Cavalli for informal discussions, and to the two anonymous reviewers, for their helpful criticism and suggestions.

\section{References}

Arrell, K. and Carver, S. (2009). Surface Roughness Scaling Trends. In Purves, R., Gruber, S., Straumann, R., and Hengl, T., editors, Geomorphometry 2009 Conference Proceedings, pages 120-123. University of Zurich, Zurich.

Beasom, S. L., Wiggers, E. P., and Giardino, J. R. (1983). A technique for assessing land surface ruggedness. Journal of Wildlife Management, 47:1163-1166.

Beyer, R. A., Mcewen, A. S., and Kirk, R. L. (2003). Meter-scale slopes of candidate MER landing sites from point photoclinometry. Journal of Geophysical Research (Planets), 108:26-1.

Bingham, R. and Siegert, M. (2009). Quantifying subglacial bed roughness in Antarctica: Implications for ice-sheet dynamics and history. Quaternary Science Reviews, 28:223-236.

Cavalli, M., Tarolli, P., Marchi, L., and Fontana, D. G. (2008). The effectiveness of airborne lidar data in the recognition of channel-bed morphology. Catena, 73(3):249-260.

Cord, A., Baratoux, D., Mangold, N., Martin, P., Pinet, P., Greeley, R., Costard, F., Masson, P. L., Foing, B., and Neukum, G. (2007). Surface roughness and geological mapping at subhectometer scale from the High Resolution Stereo Camera onboard Mars Express. Icarus, 191:38-51.

Cox, N. J. (2007). Kernel estimation as a basic tool for geomorphological data analysis. Earth Surface Processes and Landforms, 32:1902-1912.

Dartnell, P. and Gardner, J. V. (2004). Predicted Seafloor Facies from Multibeam Bathymetry and Acoustic Backscatter Data, Central Santa Monica Bay, California. Photogrammetric Engineering and Remote Sensing, 70:1081.

Day, M. J. (1979). Surface roughness as a discriminator of tropical karst styles. Zeitschrift für Geomorphologie, Suppl.-Bd. 32:1-8.

Elliot, J. K. (1989). An investigation of the change in surface roughness through time on the foreland of Austre Okstindbreen, North Norway. Computers \& Geosciences, 15:209-217.

Evans, I. S. (1972). Spatial Analysis in Geomorphology, chapter General geomorphometry, derivatives of altitude, and descriptive statistics, pages 17-90. Harper \& Row.

Evans, I. S. (1980). An integrated system of terrain analysis and slope mapping. Zeitschrift für Geomorphologie, Suppl.-Bd. 36:274-295.

Evans, I. S. (1984). Correlation structures and factor analysis in the investigation of data dimensionality: statistical properties of the Wessex land surface, England. International Symposium on Spatial Data Handling, Zurich, $1: 98-116$.

Evans, I. S. (1998). What do terrain statistics really mean? In Lane, Richards, K. S., and Chandler, J. H., editors, Landform Monitoring, Modelling and Analysis, pages 119-138. J.Wiley.

Fox, C. G. and Hayes, D. E. (1984). Quantitative Methods for Analyzing the Roughness of the Seafloor. Reviews of Geophysics and Space Physics, 23:1-48.

Frankel, K. L. and Dolan, J. F. (2007). Characterizing arid region alluvial fan surface roughness with airborne laser swath mapping digital topographic data. Journal of Geophysical Research (Earth Surface), 112:F02025.

Glenn, N. F., Streutker, D. R., Chadwick, D. J., Thackray, G. D., and Dorsch, S. J. (2006). Analysis of LiDARderived topographic information for characterizing and differentiating landslide morphology and activity. Geomorphology, 73:131-148.

Gorini, M. A. V. (2009). Physiographic Classification of the Ocean Floor: A Multi-Scale Geomorphometric Approach. In Purves, R., Gruber, S., Straumann, R., and Hengl, T., editors, Geomorphometry 2009 Conference Proceedings, pages 98-105. University of Zurich, Zurich.

GRASS Development Team (2009). Geographic Resources Analysis Support System (GRASS GIS) Software, Version 6.4.0. http://grass.osgeo.org, [accessed 05 January 2010].

Grohmann, C. H. (2004). Morphometric analysis in Geographic Information Systems: applications of free software GRASS and R. Computers \& Geosciences, 30:1055-1067.

Grohmann, C. H. and Riccomini, C. (2009). Comparison of roving-window and search-window techniques for characterising landscape morphometry. Computers \& Geosciences, 35:2164-2169.

Guth, P. L. (2003). Eigenvector Analysis of Digital Elevation Models in a GIS: Geomorphometry and Quality Control. In Evans, I. S., Dikau, R., Tokunaga, E., Ohmori, H., and Hirano, M., editors, Concepts and Modelling in Geomorphology: International Perspectives. TERRAPUB, Tokyo. 
Haneberg, W. C. (2007). Large-scale terrain visualization using SRTM Digital Elevation Models: an example from the Indian Himalaya. In Geological Society of America Annual Meeting.

Haneberg, W. C., Creighton, A. L., Medley, E. W., and Jonas, D. A. (2005). Use of LiDAR to assess slope hazards at the Lihir gold mine, Papua New Guinea. In Hungr, O., Fell, R., Couture, R., and Eberhardt, E., editors, Proceedings of International Conference on Landslide Risk Management, Vancouver, Canada, Supplementary $C D$.

Herzfeld, U. C., Mayer, H., Feller, W., and Mimler, M. (2000). Geostatistical analysis of glacier-roughness data. Annals of Glaciology, 30:235-242.

Hiller, J. and Smith, M. (2008). Residual relief separation: digital elevation model enhancement for geomorphological mapping. Earth Surface Processes and Landforms, 33(14):2266-2276.

Hobson, R. D. (1967). FORTRAN IV programs to determine the surface roughness in topography for the CDC 3400 computer. Computer Contribution State Geol. Survey Kansas, 14:1-28.

Hobson, R. D. (1972). Surface roughness in topography: quantitative approach. In Chorley, R. J., editor, Spatial analysis in geomorphology, pages 225-245. Methuer, London.

Hofierka, J., Mitasova, H., and Neteler, M. (2009). Chapter 17 Geomorphometry in GRASS GIS. In Hengl, T and Reuter, H. I., editors, Geomorphometry: Concepts, Software, Applications, volume 33 of Developments in Soil Science, pages 387-410. Elsevier, Amsterdam.

Horn, B. K. P. (1981). Hill Shading and the Reflectance Map. Proceedings of the IEEE, 69:14-47.

Hubbard, B., Siegert, M. J., and Mccarroll, D. (2000). Spectral roughness of glaciated bedrock geomorphoric surfaces: implications for glacier sliding. Journal of Geophysical Research, 165(B9):21,295-21,303.

Jenness, J. S. (2004). Calculating Landscape Surface Area from Digital Elevation Models. Wildlife Society Bulletin, $32: 829-839$

Kreslavsky, M. A. and Head, J. W. (2000). Kilometer-scale roughness of Mars: results from MOLA data analysis. Journal of Geophysical Research, 105:26,695-26,711.

Lillesand, T. M., Kiefer, R. W., and Chipman, J. W. (2004). Remote Sensing and Image Interpretation. John Wiley \& Sons, Chichester UK, sixth edition.

Lundblad, E., Wright, D. J., Miller, J., Larkin, E. M., Rinehart, R., Naar, D. F., Donahue, B. T., Anderson, S. M., and Battista, T. (2006). A Benthic Terrain Classification Scheme for American Samoa. Marine Geodesy, 29:89-111.

MacMillan, R. A. and Shary, P. A. (2009). Chapter 9 Landforms and Landform Elements in Geomorphometry. In Hengl, T. and Reuter, H. I., editors, Geomorphometry: Concepts, Software, Applications, volume 33 of Developments in Soil Science, pages 227-254. Elsevier, Amsterdam.

Mark, D. M. (1975). Geomorphometric parameters: a review and evaluation. Geografiska Annaler. Series A, Physical Geography, 57:165-177.

Mason, D. C., Cobby, D. M., Horritt, M. S., and Bates, P. D. (2003). Floodplain friction parameterization in two-dimensional river flood models using vegetation heights derived from airborne scanning laser altimetry. Hydrological Processes, 17(9):1711-1732.

Mckean, J. and Roering, J. (2004). Objective landslide detection and surface morphology mapping using highresolution airborne laser altimetry. Geomorphology, 57:331-351.

Minár, J. and Evans, I. S. (2008). Elementary forms for land surface segmentation: The theoretical basis of terrain analysis and geomorphological mapping. Geomorphology, 95(3-4):236-259.

Neteler, M. and Mitasova, H. (2008). Open Source GIS : A GRASS GIS Approach, Third Edition (The International Series in Engineering and Computer Science), volume 773. Springer, New York.

Olaya, V. (2009). Chapter 6. Basic Land-Surface Parameters. In Hengl, T. and Reuter, H. I., editors, Geomorphometry: Concepts, Software, Applications, volume 33 of Developments in Soil Science, pages 141-169. Elsevier, Amsterdam.

Papasaika, H. and Baltsavias, E. P. (2009). Investigations on the Relation of Geomorphological Parameters to DEM Accuracy. In Purves, R., Gruber, S., Straumann, R., and Hengl, T., editors, Geomorphometry 2009 Conference Proceedings, pages 162-168. University of Zurich, Zurich.

Philip, G. M. and Watson, D. F. (1986). A method for assessing local variation among scattered measurements. Mathematical Geology, 18:759-764.

Pike, R. J., Evans, I. S., and Hengl, T. (2009). Chapter 1. Geomorphometry: a brief guide. In Hengl, T. and Reuter, H. I., editors, Geomorphometry: Concepts, Software, Applications, volume 33 of Developments in Soil Science, pages 3-30. Elsevier, Amsterdam.

Rabus, B., Eineder, M., Roth, R., and Bamler, R. (2003). The Shuttle Radar Topography Mission-a new class of digital elevation models acquired by spaceborne radar. ISPRS Journal of Photogrammetry $\&$ Remote Sensing, $57: 241-262$.

Reuter, H. I., Neison, A., Strobl, P., Mehl, W., and Jarvis, A. (2009). A first assessment of aster gdem tiles for absolute accuracy, relative accuracy and terrain parameters. In Geoscience and Remote Sensing Symposium,2009 IEEE International,IGARSS 2009, volume 5, pages $\mathrm{V}-240-\mathrm{V}-243$.

Rose, J. ans Smith, M. J. (2008). Glacial geomorphological maps of the Glasgow region, western central Scotland. Jounal of Maps, v2008:399-416.

Schmidt, J., Evans, I. S., and Brinkmann, J. (2003). Comparison of polynomial models for land surface curvature calculation. International Journal of Geographical Information Science, 17:797-814.

Shepard, M. K., Campbell, B. A., Bulmer, M. H., Farr, T. G., Gaddis, L. R., and Plaut, J. J. (2001). The roughness of natural terrain: A planetary and remote sensing perspective. Journal of Geophysical Research, 106:32777-32795. 
Siegert, M. J., Taylor, J., Payne, A. J., and Hubbard, B. (2004). Macro-scale bed roughness of the Siple Coast ice streams in west Antarctica. Earth Surface Processes and Landforms, 29:1591-1596.

Silk, J. (1979). Statistical concepts in geography. George Allen \& Unwin, Ltd.

Siska, P. P., Goovaerts, P., Hung, I. K., and Bryant, V. M. (2005). Predicting ordinary kriging errors caused by surface roughness and dissectivity. Earth Surface Processes and Landforms, 30:601-612.

Smith, M. J., Rose, J., and Booth, S. (2006). Geomorphological mapping of glacial landforms from remotely sensed data: An evaluation of the principal data sources and an assessment of their quality. Geomorphology, $76: 148-165$

Stone, R. O. and Dugundji, J. (1965). A study of microrelief - its mapping, classification and quantification by means of a Fourier analysis. Engineering Geology, 1:89-187.

Taud, H. and Parrot, J. F. (2005). Measurement of DEM roughness using the local fractal dimension. Géomorphologie: relief, processus, environnement, 10:327-338.

Taylor, J., Siegert, M. J., Payne, A. J., and Hubbard, B. (2004). Regional-scale bed roughness beneath ice masses: measurement and analysis. Computers $\& 5$ Geosciences, 30:899-908.

Tobler, W. R. (1970). A computer model simulation of urban growth in the detroit region. Economic Geography, $46(2): 234-240$.

Valentine, P. C., Fuller, S. J., and Scully, L. A. (2004). Terrain Ruggedness Analysis ans Distribution of Boulder Ridges in the Steallwagen Bank National Marine Sanctuary Region. In 5th International Symposium on Marine Geological and Biological Habitat Mapping (GeoHAB), Galway, Ireland.

Van Der Veen, C. J., Krabill, Csatho, and Bolzan, J. F. (1998). Surface roughness on the Greenland ice sheet from airborne laser altimetry. Geophysical Research Letters, 25:3887-3890.

Washtell, J., Carver, S., and Arrell, K. (2009). A Viewshed Based Classification of Landscapes Using Geomorphometrics. In Purves, R., Gruber, S., Straumann, R., and Hengl, T., editors, Geomorphometry 2009 Conference Proceedings, pages 44-49. University of Zurich, Zurich.

Wilson, M. F. J., O'Connell, B., Brown, C., Guinan, J. C., and Grehan, A. J. (2007). Multiscale Terrain Analysis of Multibeam Bathymetry Data for Habitat Mapping on the Continental Slope. Marine Geology, 30:3-35.

Wise, S. M. (2000). Assessing the quality for hydrological applications of digital elevation models derived from contours. Hydrological Processes, 14:1909-1929.

Wise, S. M. (2007). Effect of differing DEM creation methods on the results from a hydrological model. Computers EG Geosciences, 33:1351-1365. 